\title{
Assessment of Pregnant Women Toxoplasmosis by ELISA Method in Miandoab City, Iran
}

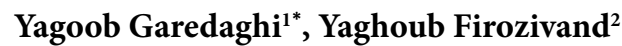

\begin{abstract}
Objectives: Immunity to Toxoplasma gondii infection is known to be a critical point for women during pregnancy. Non immune pregnant women may at risk to be infected with the parasite. The parasite can be transmitted via placenta and causes adverse effects in fetus. The main objective of the present work was to study sero-prevalence of Toxoplasma infection in pregnant women referred to Health Center in Miandoab.

Materials and Methods: Totally 200 blood samples were collected from 18-40 years pregnant women referred to Health Center in Miandoab during one year. The sera were tested for IgG and IgM titration with enzyme-linked immunosorbent assay (ELISA) kits. In addition, demographic characteristics of the women were obtained through appropriate questionnaires.

Results: Positive IgG and IgM titers were identified in the sera of (39.5\%) and (2.5\%), of the pregnant women, respectively. The higher frequency of positive titers was associated with older age. In addition, $94.42 \%$ of the women with positive titer had a history of contact with cats.

Conclusion: Regarding the prevalence rate of $60 \%$ in non-immune pregnant women in Miandoab, the preventive measurements in nutrition and contact with cats should be considered by the women. We recommend the sera of the pregnant women should be monitored for Toxoplasma infection at least once a pregnancy period, particularly during the first trimesters of pregnancy.

Keywords: Toxoplasma gondii, Pregnant women, ELISA method, Iran
\end{abstract}

\section{Introduction}

The intracellular protozoan parasite, Toxoplasma gondii, causes infection in men and animals. The primary hosts which harbour the intestinal, sexual stage are cats $(1,2)$. Transmission to humans happens mainly by eating raw or undercooked contaminated meat $(3,4)$, raw cow's milk and birds eggs, swallowing oocysts dis-charged in faeces of infected cats, inoculation of trophozoites through the skin, or by inhalation (5-7). Transmission from a mother infected during pregnancy, to the fetus causes congenital toxoplasmosis (8-10). Human toxoplasmosis is worldwide. In adolescence and adulthood, most infections are subclinical or run a very mild clinical course (11). Toxoplasmosis is a systemic infection, always accompanied by the production of serum anti-bodies at high titre. After the acute stage antibodies persist at lower titre, usually throughout life. The number of seropositive persons in a population, therefore, increases with age. Although antibodies for T. gondii have been found in the sera of humans and animals throughout the world, the proportion of subjects with positive reactions varies consider-ably by geographic area, age and test method used (11-13). The risk, by age, of acquiring infection is not uniform throughout the world. It has been reported that prevalence of seropositivity among Eskimos is zero, among Brazilians, 72\%
(14). Frequency among the population of the United States ranges from $10 \%$ to $20 \%$ in young adults and from $35 \%$ to $70 \%$ in older persons (11). Little is known about prevalence of T. gondii infection in Iran. The present study was undertaken to determine the prevalence of toxoplasmosis in pregnant women in Miandoab city, Iran for Toxoplasma IgG antibodies. Since very high IgG antibody levels may correlate with current infection, IgM testing may be used for differential diagnosis. Detection of IgM antibodies establishes the diagnosis of recently acquired or reactivated infection, but these antibodies soon disappear or decrease to very low levels followed by the appearance of IgG which stays longer. It was also planned to determine T. gondii IgM antibodies in pregnant women who were positive for toxoplasma IgG antibodies.

\section{Materials and Methods}

This cross-sectional study was performed from September to October 2014 in Miandoab city, north-west Iran. The city has a moderate and semi-humid climate. In the current survey, sample size was calculated considering a prevalence of $35 \%$, a degree of precision of $4(\mathrm{~d}=0.04)$ and $95 \%$ CI. Consequently, the sample size was calculated as 200 pregnant women. 


\section{Collecting Samples}

The objects were women referred to Health Center in Miandoab for routine examinations of pregnancy. A questionnaire containing sociodemographic and behavioral habits was designed and completed for individuals. Overall, 200 blood samples were collected and sera separated by blood centrifugation at $3000 \mathrm{rpm}$ for 5 minutes. Serum samples were transferred to the laboratory and stored at $-20^{\circ} \mathrm{C}$ until use.

\section{Analyzing Samples}

The anti-T. gondii IgG and IgM antibodies were tested with commercial enzyme-linked immunosorbent assay (ELISA) kit (Pishtaz Teb Zaman, Tehran, Iran) according to manufacturer instructions and results read by an automated ELISA reader machine (Avecina, Pishtaz Teb Zaman, Tehran, Iran). All samples were conducted as a single test. Standards with three different concentrations were employed to ensure kits were working properly and technical procedures were performed correctly.

\section{Statistical Analysis}

ELISA results and data from questionnaires were analyzed employing chi-square statistical test with 95\% CI using SPSS version 16 . The correlation between T. gondii infection with some variables such as age, living place (urban/ rural), education, occupation, cat or other animals ownership, soil contact, consumption of raw/undercooked meat or egg, consumption of raw/unpasteurized milk, vegetables washing method, frequency of consuming vegetables was estimated.

\section{Results}

The overall seroprevalence of T. gondii infections among pregnant women referred to Health Center in Miandoab was $41 \%(82 / 200)$. The IgG and IgM antibodies against T. gondii were positive in $79 / 200$ cases $(39.5 \%)$ and $5 / 200$ cases $(2.5 \%)$, respectively. Two pregnant women (1\%) indicated both IgG and IgM antibodies against T. gondii. The results of seroprevalence along with personal and sociodemographic data are indicated in Table 1.

The correlation between age $(P=0.042)$ and soil contact $(P=0.002)$ with the $T$. gondii infection was statistically significant. No significant relationship was seen between toxoplasmosis and other tested variables.

\section{Discussion}

This study revealed a seroprevalence of 39.5\% (79/200) and $2.5 \%(5 / 200)$ for IgG and IgM antibodies against $T$. gondii in pregnant women in Miandoab city, respectively. Congenital toxoplasmosis can lead to a wide variety of manifestations from spontaneous abortion and still-birth to hydrocephalus or microcephalus, cerebral calcifications and retinochoroiditis in the fetus and infant $(11,12)$. Studies had been performed to evaluate the T. gondii infection in pregnant women or child bearing age in some countries

Table 1. Prevalence of Specific anti-Toxoplasma IgG and IgM Antibodies and Sociodemographic Data in Pregnant Women in Miandoab, Iran

\begin{tabular}{|c|c|c|c|c|c|}
\hline \multirow{2}{*}{$\begin{array}{l}\text { Sociodemographic } \\
\text { Characteristics }\end{array}$} & \multirow{2}{*}{$\begin{array}{l}\text { No. of } \\
\text { Tested Women }\end{array}$} & \multicolumn{2}{|c|}{ Prevalence of Toxoplasma gondii IgG } & \multicolumn{2}{|c|}{ Prevalence of Toxoplasma gondii IgM } \\
\hline & & No. & (\%) & No. & (\%) \\
\hline \multicolumn{6}{|l|}{ Age group (y) } \\
\hline$\leq 20$ & 22 & 6 & 27.3 & 1 & 4.5 \\
\hline $21-30$ & 141 & 49 & 34.7 & 4 & 2.8 \\
\hline$>30$ & 37 & 19 & 51.35 & 1 & 2.7 \\
\hline Total & 200 & 79 & 39.5 & 5 & 2.5 \\
\hline \multicolumn{6}{|l|}{ Location } \\
\hline Urban & 115 & 44 & 38.2 & 7 & 6.08 \\
\hline Rural & 85 & 37 & 43.5 & 2 & 2.3 \\
\hline \multicolumn{6}{|l|}{ Education } \\
\hline None & 10 & 4 & 40 & 1 & 10 \\
\hline Elementary school & 38 & 20 & 52.6 & 2 & 5.2 \\
\hline Guidance school & 48 & 21 & 43.75 & 2 & 4.1 \\
\hline High school & 83 & 31 & 37.3 & 4 & 4.8 \\
\hline University & 21 & 7 & 33.3 & 1 & 4.7 \\
\hline \multicolumn{6}{|l|}{ Occupation } \\
\hline Employed & 16 & 5 & 31.2 & 1 & 6.25 \\
\hline Unemployed & 184 & 75 & 40.76 & 12 & 6.52 \\
\hline \multicolumn{6}{|l|}{ Gestational age } \\
\hline First trimester & 92 & 37 & 40.21 & 3 & 3.26 \\
\hline Second trimester & 25 & 10 & 40 & 1 & 4 \\
\hline Third trimester & 83 & 32 & 38.5 & 1 & 1.2 \\
\hline
\end{tabular}


and different seroprevalences were estimated. The reported seroprevalences of $T$. gondii infection were $51.4 \%$ in Saudi Arabia (13), 59\% in Argentina (14), 43\% in Austria (15), 30\% in Spain (16), $22.1 \%$ in Slovakia (17), $24.6 \%$ in Turkey (18) and $92.5 \%$ in Ghana (19). The prevalence rate of $29.1 \%$ and $0.8 \%$ for anti-IgG and IgM antibodies in pregnant women was estimated in Zair, Nigeria (20). Among pregnant women tested in rural Durango State, Mexico, IgG antibodies against $T$. gondii infection varied from $0 \%$ to $20 \%$ in different communities. Overall, $8.2 \%$ had IgG and 2.3\% had IgM antibodies, too (21).

In Iran, the prevalence rates of $22.7 \%$ and $31 \%$ were estimated in pregnant women form Kermanshah (22) and Khorram-Abad (23), whereas the rate of T. gondii infection was $20.1 \%$ and $19.2 \%$ in pregnant women of Isfahan (24) and Sabzavar (25), respectively. Abdi et al found the prevalence rate of $44.8 \%$ of infection in Ilam province (26). A study in Kerman, South eastern Iran, reported a prevalence of $46.9 \%$ in pregnant women (27). In Zanjan city, located in northwest of Iran, $1.4 \%$ and $37.2 \%$ of tested pregnant women had IgG and IgM antibodies against $T$. gondii, respectively (28-31).

North of Iran has suitable climate for oocyst sporulation of $T$. gondii, so high prevalence of infection is expected there. The present study showed a high rate of IgG anti- $T$. gondii anti-body (39.5\%) positive along with a relatively low prevalence rate for IgM $(2.5 \%)$ in pregnant women in Miandoab city.

However, in the present study the relation of the Toxoplasma infection with age was statistically significant that is in concordance with results of some previous studies in other parts of Iran such as Bandar Abbas (32), Hamadan (34), Khorram-Aabad $(23,36,37)$ and Alashtar $(35,38,39)$. In Turkey the percentages of seropositivity of IgG antibody for T. gondii and Rubella and Cytomegalovirus are 31.5\%, $90 \%$ and $73.3 \%$ respectively. The percentages of seropositivity of IgM antibody for T. gondii and Rubella and Cytomegalovirus are $2.0 \%, 0.6 \%$ and $3.7 \%$ respectively $(40)$.

Also, our results indicated a significant correlation between T. gondii infection and soil contact that is not surprising since north-west of Iran has appropriate climate for oocyst sporulation and contacting with oocyst infected soil is one of the common routes of human infection. In the current study there was no statistically significant relationship between toxoplasmosis and some tested criteria such as living place (urban/rural), education, occupation, cat or other animals ownership, or egg, consumption of raw/unpasteurized milk, vegetables washing method, frequency of consuming vegetables. Whereas significant correlation was reported between the infection with education, consumption of raw/undercooked meat and frequency of consuming vegetables $(41,42)$ in some previous studies in Iran.

\section{Conclusion}

The results of this study indicate that about $60 \%$ of pregnant women in this city had no contact with the parasite and are at risk for congenital toxoplasmosis, so, preventive measures and establishing diagnostic toxoplasmosis tests during pregnancy are warranted.

\section{Ethical Issues}

We have no ethical issues to declare.

\section{Conflict of Interests}

The authors declare no conflict of interests.

\section{Financial Support}

None.

\section{Acknowledgments}

The authors wish to thank the Islamic Azad University, Malekan Branch, Malekan, Iran for the laboratory instrumental supports, and all laboratory technicians for technical aids in this project.

\section{References}

1. Boyle JP, Radke JR. A history of studies that examine the interactions of Toxoplasma with its host cell: emphasis on in vitro models. Int J Parasitol. 2009;39(8):903-914. doi:10.1016/j.ijpara.2009.01.008.

2. Montoya J, Liesenfeld O. Toxoplasmosis. Lancet. 2004; 363(9425):1965-1976.

3. Weiss LM, Dubey JP. Toxoplasmosis: A history of clinical observations. Int J Parasitol. 2009;39(8):895-901. doi:10.1016/j.ijpara.2009.02.004.

4. Dubey JP. The History of Toxoplasma gondii - The First 100 Years. J Eukaryot Microbiol. 2008;55(6):467-475. doi:10.1111/j.1550-7408.2008.00345.x.

5. Remington JS, Thulliez P, Montoya JG. Recent developments for diagnosis of toxoplasmosis. J Clin Microbiol. 2004;42(3):941-945.

6. Dubey J, Beattie C, Toxoplasmosis of Animals and Man. Boca Raton, Florida: CRC Press; 1988.

7. Tenter AM, Heckeroth AR, Weiss LM. Toxoplasma gondii: from animals to humans. Int J Parasitol. 2000;30(1213):1217-1258.

8. Speer CA, Dubey JP. Ultrastructural differentiation of Toxoplasma gondii schizonts (types B to E) and gamonts in the intestines of cats fed bradyzoites. Int J Parasitol. 2005;35(2):193-206. doi:10.1016/j.ijpara.2004.11.005.

9. Reis MM, Tessaro MM, D’azevedo PA. Perfil sorológico para toxoplasmose em gestantes de um hospital público de Porto Alegre. Rev Bras Ginecol Obstet. 2006;28(3):158-64.

10. Mostafavi SN, Jalali Monfared L. Toxoplasmosis epidemiology in Iran: a systematic review. Journal of Isfahan Medical School. 2012;30(176):1-15.

11. Remington J, McLeod R, Thulliez PH, Desmonts G. Infectious diseases of the fetus and newborn infant. In: Remington J, Klein J, Wilson C, Baker C, eds. Toxoplasmosis. Philadelphia: Elsevier Saunders; 2006.

12. Wellington AO, Oladipo OO, Chimere OA, Oladele TO, Anunobi CC, Soyebi K. Congenital toxoplasmosis: a review of its pathology, immune response and current treatment options. Sierra Leone J Biomed Res. 2009;1(1):2-20.

13. Al-Mohammad $\mathrm{H}$, Balaha $\mathrm{M}$, Al-Moghannum $\mathrm{M}$. Toxoplasmosis among the pregnant women attending a Saudi maternity hospital: seroprevalence and possible risk 
factors. Ann Trop Med Parasitol. 2010;104(6):493-504. doi: 10.1179/136485910x12786389891443.

14. Fuente M, Bovone N, Cabral G. Profilaxis de la toxoplasmosis prenatal. Medicina (Buenos Aires). 1997;57:155-160.

15. Aspöck H, Pollak A. Prevention of pre natal toxoplasmosis by serological screening of pregnant women in Austria. Scand J Infect Dis Suppl. 1992;84:32-7.

16. Jaqueti J, Hernandez-Garcia R, Nicolas D, MartinezHernandez D, Navarro-Gallar F, Garcia-Esteban RJ. Serology against Toxoplasma gondii in pregnant women. Development of prevalence rates in the course of 4 years (In Spanish). Rev Clín Esp. 1991:278-80.

17. Studenicová C, Ondriska F, Holková R. Sero-prevalence of Toxoplasma gondii among pregnant women in Slovakia (In Slovak). Epidemiol Mikrobiol Imunol. 2008;57(1):8-13.

18. Akyar I. Seroprevalence and coinfections of Toxoplasma gondii in childbearing age women in Turkey. Iran J Public Health. 2011;40(1):63-67.

19. Ayi I, Edu SAA, Apea-Kubi KA, Boamah D, Bosompem KM, Edoh D. Seroepidemiology of toxoplasmosis amongst pregnant in the greater ACCRA region of Ghana. Ghana Med J. 2009;43(3):107-114.

20. Ishaku B, Ajogi I, Umoh JU, Lawal I, Randawa AJ. Seroprevalence and risk factors for Toxoplasma gondii infection among antenatal women in Zaria, Nigeria. Res J Med Med Sci. 2009;4(2):483-438.

21. Alvarado-Esquivel C, Torres-Castorena A, Liesenfeld O, et al. Seroepi-demiology of Toxoplasma gondii infection in pregnant women in rural Durango, Mexico. J Parasitol. 2009; 95(2):271-274.

22. Athari A, Shojaeian S, eliasi O, delfani K. Seroprevalence of Toxoplasma anti-bodies among pregnant women in Kermanshah. Med J Islam Repub Iran. 1993;8(2):93-66.

23. Cheraghipour K, Falah M, Sheykhian A, Sardarian K, Rostamnezhad M, Maghsoudi A. Seroprevalence of toxoplasmosis in pregnant women admitted to the health centers of Khorram-Abad city, Iran (Persian). Scientific Journal of Hamadan University of Medical Sciences and Health Services. 2010;17(3):51-46.

24. Jalayer $\mathrm{T}$, Alame $\mathrm{T}$. Seroprevalence of congenital toxoplasmosis in neonatal born in Isfahan. 2nd Congress of Parasitology; 1997; Tehran, Iran.

25. Moalaee H, Shirzad E, Namazi M. Seroepidemiology of toxoplasmosis and its eye complication in pregnant women (Persian). Sabzavar Univ Med Sci J. 1992:21-3.

26. Abdi J, Shojaee S, Mirzaee A, Keshavarz H. Seroprevalence of toxoplasmosis in pregnant women in Ilam province, Iran. Iran J Parasitol. 2008; 3(2):34-7.

27. Keshavarz H, Mamishi S, Daneshvar H. The prevalence of Toxoplasma infection in hospitalized patients in selected hospitals of Kerman (Persian). J Med Sci Kerman. 2000;7(3):129-136.

28. Hajsoleimani F, Ataeian A, Nourian A, Mazloomzadeh S. Seroprevalence of Toxoplasma gondii in pregnant women and bioassay of IgM positive cases in Zanjan, Northwest of Iran. Iran J Parasitol. 2012;6(2):82-86.
29. Ghorbani M, Edrisian G, Assad N. Serological survey of toxoplasmosis in northern of Iran. Trans R Soc Trop Med Hyg. 1978;72(4):369-371.

30. Saffar M, Ajami A, Moslemi Zadeh N. Prevalence of Toxoplasma gondii in pregnancy in Sari 1997-1998 (Persian). Journal of Mazandaran University of Medical Sciences. 1999;9(24):1-5.

31. Saeedi M, Veghari GR, Marjani A. Seroepidemiologic evaluation of anti-Toxoplasma antibodies among women in North of Iran. Pak J Bio Sci. 2007;10(14):2359-2362.

32. Setoodeh Jahromi A, Safa O, Zare S, Davoodian P, Farshid Far GR. Prevalence of Toxo-plasma antibodies in pregnant women referred to Shariati Hospital, Bandar Abbas, Iran, 1999-2000 (Persian). Journal of Hormozgan University of Medical Sciences. 2003;4(6):25-30.

33. Kamyabi Z, Atapour M. Investigation of the prevalence of Toxoplasma antibodies in women during marriage consultation in Kerman city (Persian). J Med Sci Kerman. 1999;6(3):127-133.

34. Fallah M, Rabiee S, Matini M, Taherkhani $H$. Seroepidemiology of toxoplasmosis in primigravida women in Hamadan, Islamic Republic of Iran, 2004. East Mediterr Health J. 2008;14(1):163-171.

35. Cheraghipour K, Sheykhian A, Maghsoudi A, Hejazi Z, Rostamnezhad M. Seroprevalence study of toxoplasmosis in pregnant women referred to Aleshtar rural and urban health centers in 2008. Yafteh. 2009;11(3):65-74.

36. Sharifi-Mood B, Hashemi-Shahri M, Salehi M, Naderi M, Naser-poor T. Seroepidemiology of Toxoplasma Infection in the Pregnant Women in Zahedan, Southeast of Iran. J Res Health Sci. 2004;4(1):1-3.

37. Parvizpour F, Hajighasemlo S, Hasani S, et al. Toxoplasmosis infection in the pregnant women in the first half of pregnancy, in Kamyaran in 2008 (Persain). Scientific Journal of Kurdistan University of Medical Sciences. 2008;15(1):72-8.

38. Garedaghi Y, Safarmashaei S. Survey of Toxoplasma contamination in kidney recipient patients by ELISA method and comparison it with control group in Tabriz (East-azerbaijan), Iran. Adv Environ Biol. 2011;5(4):769772 .

39. Sharbatkhori M, Dadi Moghaddam Y, Pagheh AS, Mohammadi R, Hedayat Mofidi H, Shojaee S. Seroprevalence of Toxoplasma gondii infections in pregnant women in Gorgan city, Golestan province, Northern Iran2012. Iran J Parasitol. 2014;9(2):181-187.

40. Gün I, Ertuğrul S, Kaya N, Akpak YK. Seroprevalence among Turkish pregnant women. Healthmed J. 2012;6(7): 2471-2476.

41. Afshari F, Imani AM, Najjari Asl S. Evaluation of testosterone and alkaline phosphatase activity changes in epidydimis of Toxoplasma gondii infected rats. Int J Womens Health Reprod Sci. 2013;1(2):64-71.

42. Garedaghi Y. Important zoonotic helminthes affecting the human eye. Crescent J Med Biol Sci. 2016;3(3):73-74.

Copyright (C) 2017 The Author(s); This is an open-access article distributed under the terms of the Creative Commons Attribution License (http://creativecommons.org/licenses/by/4.0), which permits unrestricted use, distribution, and reproduction in any medium, provided the original work is properly cited. 